\title{
The use of nanosized additives in the modification of brick loam
}

\author{
Andrey Bogdanov ${ }^{1}$ *0000-0002-0129-5942], Azat Mavlyuberdinov ${ }^{1[0000-0003-2111-4712]}$, and Evgeniya \\ Nurieva $^{2}$ \\ ${ }^{1}$ Kazan State University of Architecture and Engineering, 420043, Zelenaya st., Kazan, Russia \\ ${ }^{2}$ Kazan Federal University, 420008, Kremlevskaya st., Kazan, Russia
}

\begin{abstract}
The effect of nanosized additives on the strength properties of ceramics based on fusible brick loam of the Klyuchischenskoye deposit has been studied. In general, all nanosized additives selected for the study had a positive effect on the strength properties of ceramics. The greatest increase in strength, when using nanosized silica ash Laksil 30, was $70 \%$, in relation to the control sample. When using silica ash, an increase in the content of the amorphous phase in the shard after firing is noted against the background of a decrease in its porosity, which causes an increase in strength characteristics. The nature of the destruction of the samples also differed. The destruction of the control sample was accompanied by the formation and gradual opening of cracks. The destruction of the modified samples was more fragile in comparison with the control. Thus, the effectiveness of nanosized additives on the strength properties of ceramics is shown.
\end{abstract}

Keywords: clay, loam, nanoadditives, ceramics.

\section{Introduction}

To date, the construction standards have been completely revised, new stringent standards have been introduced for the resistance to heat transfer of enclosing structures even in countries with a warm climate [1-3]. Moving away from the construction of buildings with massive enclosing structures, in favor of «thermos buildings», the inertial component of the outer walls is reduced, which, for example, can affect both the timing of the postponement of a later start of the heating period and the decrease in heat carrier consumption. But first of all, in such buildings, the conditions of comfort for a person's stay deteriorate. Especially if we compare them with buildings with wooden or all-ceramic walls.

Buildings constructed from ceramic bricks are energy- and resource-efficient, reducing maintenance and service costs. Ceramic bricks, thanks to their micropore systems, being a «breathable material», provide excellent thermal insulation properties to buildings.

Thus, construction is no longer possible without the use of effective insulation [4-9], which, in addition to reducing heat loss through the enclosing structures, can reduce the load on the foundations of buildings. In addition to reducing the material consumption of

* Corresponding author: gold04@mail.ru 
construction and significant savings on the construction of foundations, reducing the weight of the building structure will increase the usable area of the object by reducing the thickness of the walls while maintaining the external dimensions of the object. In the construction market a large range of insulation materials of organic, organo-mineral and mineral nature is used.

As an alternative to the used heaters, a ceramic heater is proposed that performs a heatsaving or decorative-heat-saving function.

In terms of its territory, Russia is the largest state in the world (the total area is more than 17 million square meters). Geographically, not all regions have sufficient quarry reserves of clay raw materials that allow the production of high-quality building ceramics, especially highly porous ceramics. Brick loams, highly sensitive to drying, are widespread, but the production of wall products from them is accompanied by a number of difficulties. This is a low grade of manufactured products and an unsatisfactory appearance, along with the difficulties of drying raw materials from such raw materials, which takes quite a long time. To correct the performance properties of ceramics based on such raw materials, «traditionally» plastic «fat» clays are used. This leads to the multicomponent composition of the charge, the need for its averaging and homogeneity. The volume of imported clays in the charge ranges from 15-50\%, which entails an increase in the volume of cargo transportation. There is also an alternative to high-tonnage additives - additives from the composition of low-tonnage construction chemicals, incl. nano-sized additives.

This article is devoted to solving the problems of increasing the operational characteristics of a ceramic shard by nano-sized additives, incl. to increase the degree of filling of clay raw materials with porous additives.

\section{Materials and methods}

The research was carried out on the example of brick loams of the Klyuchishchenskoye deposit in the Republic of Tatarstan. Such loams belong to the category of polymineral lowmelting moderately plastic low-dispersed loams and show low grades of shards. The main clay-forming mineral is montmorillonite with a content of $36 \%$ and a high content of quartz sand of $48-62 \%$ in a free state.

Previously, the influence of multilayer carbon nanotubes [10-15] and surfactants [1623] on the operational and drying properties of brick loams has already been studied, and positive results of such a modification have been obtained. The goal of further improving the operational characteristics of ceramics, in particular, increasing its strength properties, was decided by the choice of modifiers from the composition of nanosized ones. Following nanosized additives were selected for testing, the production of which was established by Russian manufacturers:

1 alumina sol;

2 silicones: Laksil 30 и Laksil 30-Al;

$31 \%$ aqueous colloidal dispersions of carbon nanotubes (CNTs) Taunit-M in a $1 \%$ solution of phenol-formaldehyde resin;

$41 \%$ aqueous colloidal dispersions of graphene nanoplates (GNPs) in a $1 \%$ solution of phenol-formaldehyde resin.

Alumina sol is an aqueous colloidal solution of aluminum oxide AL2O3. It is a polydisperse system, the particle size of which is in the range of 80-200 $\mathrm{nm}$. The $\mathrm{pH}$ of the alumina sol is in the range of 3.8-4.2. Alumina sol exhibits are irreversible and have best binding properties after calcination at a temperature of 500-600 ${ }^{\circ} \mathrm{C}$, forming active $\alpha$ $\mathrm{Al}_{2} \mathrm{O}_{3}$, as a result of which it can be used up to a temperature of $2000^{\circ} \mathrm{C}$. The alumina particles carry a positive charge, which should facilitate their adsorption onto the surface of clay particles and the inter-package space. 
Silica sol (colloidal silica, silicic acid sol) is a colloidal solution consisting of a dispersion medium, which is specially prepared water, and a dispersed phase, which is represented by nanosized micelles of amorphous silica. The $\mathrm{pH}$ of Laksil 30 is in the range of 8.5-10, and the $\mathrm{pH}$ of Laksil 30-Al is in the range of 2.2-4.

As an alternative to alumina sol and silica sols, which are nanosized additives, $1 \%$ aqueous colloidal dispersions of Taunit-M carbon nanotubes (CNTs) and graphene nanoplates (GNP) in a $1 \%$ solution of phenol-formaldehyde resin were tested.

Characteristics of CNT Taunit-M: outer diameter 8-15 nm; inner diameter 4-8 nm; length $\geq 2 \mu \mathrm{m}$; specific surface $\geq 30000-32000 \mathrm{~cm} / \mathrm{g}$; thermal resistance in air $\leq 600{ }^{\circ} \mathrm{C}$.

Characteristics of graphene nanoplates (GNP): number of graphene layers 15-25 nanoplastic thickness 6-8 $\mathrm{nm}$; the size of the nanoplates in the plane is $2-10$ microns;

The introduction of nano-modifiers into the clay mixture was carried out in order to increase the strength characteristics of the spatial framework of a ceramic shard, including for the development of a porous and cellular structure.

Nano-modifying additives, in order to improve the volume distribution of raw materials, were introduced into loam, which had been preliminarily dried and milled to a specific surface of $2400-3000 \mathrm{~cm}^{2} / \mathrm{g}$, in the composition of mixing water with the calculation of bringing the clay mass to a state of normal molding moisture corresponding to $20 \%$ of the mass loam. Subsequently, the modified clay mass was mixed until uniform.

\section{Results}

The physical and mechanical characteristics of ceramics during the modification of the loam of the Klyuchishchenskoye deposit with nanosized additives from among those selected for testing are given in Table 1 .

Table 1. Characteristics of a shard from Klyuchischenskoye loam $\left(1000{ }^{\circ} \mathrm{C}\right)$

\begin{tabular}{|c|c|c|c|c|c|c|}
\hline \multicolumn{5}{|c|}{$\begin{array}{l}\text { Content of an aqueous solution of the modifier, \% by } \\
\text { weight of loam }\end{array}$} & \multicolumn{2}{|c|}{ properties crock } \\
\hline \multirow{2}{*}{ alumina sol } & \multicolumn{2}{|c|}{ silica sol } & \multirow{2}{*}{$\begin{array}{c}\text { carbon } \\
\text { nanotubes }\end{array}$} & \multirow{2}{*}{$\begin{array}{l}\text { graphene } \\
\text { nanoplates }\end{array}$} & \multirow{2}{*}{$\begin{array}{l}\text { density, } \\
\mathrm{kg} / \mathrm{m}^{3}\end{array}$} & \multirow{2}{*}{$\begin{array}{l}\text { compressive } \\
\text { strength, } \mathrm{MPa}\end{array}$} \\
\hline & 30 & $30 \mathrm{Al}$ & & & & \\
\hline \multicolumn{5}{|l|}{ Control } & 1783.81 & 15.7 \\
\hline 0.01 & & & & & 2034.61 & 21.1 \\
\hline \multirow[t]{9}{*}{0.1} & & & & & 1998.73 & 19.6 \\
\hline & 0.01 & & & & 2055.25 & 21.8 \\
\hline & 0.1 & & & & 2043.22 & 26.7 \\
\hline & & 0.01 & & & 2045.17 & 23.1 \\
\hline & & 0.1 & & & 1985.82 & 20.8 \\
\hline & & & 0.01 & & 1820.85 & 17.1 \\
\hline & & & 0.1 & & 1807.56 & 17.5 \\
\hline & & & & 0.01 & 1796.24 & 11.7 \\
\hline & & & & 0.1 & 1841.24 & 19.5 \\
\hline
\end{tabular}

It can be seen that all nanosized additives made it possible to increase the strength characteristics of the ceramic shard. The best results when testing the strength characteristics of a shard from brick loam of the Klyuchischenskoye deposit for compression were obtained when modifying the Klyuchishenskoye loam with silica sol Laksil 30. The average increase in strength was up to $70 \%$ in relation to the control samples.

The fracture pattern of the control sample differed from that modified by silica sol Laksil 30. Thus, during the destruction of the control sample with an increase in the load, 
the formation of longitudinal cracks to the application of force was observed throughout the sample volume, their opening with an increase in the load, followed by the destruction of the sample throughout the volume. During loading of the modified specimens, upon reaching the breaking stresses, the formation of thinning was observed in the center of the specimen. As a result, the destruction of the modified samples occurred with the formation of two pyramids, the centers facing the center of the sample. The destruction of the modified Laksil 30 samples was more fragile.

In order to explain the effect of the increase in the strength characteristics of the samples during the modification of Klyuchischenkoye loam with Laksil 30 silica sol, X-ray phase analysis and computed tomography of a ceramic shard of the control and modified samples were carried out.

The spectra obtained as a result of X-ray phase analysis are shown in Fig. 1. It can be seen that the main difference between the control and modified samples is the quantitative content of the amorphous phase.

a)

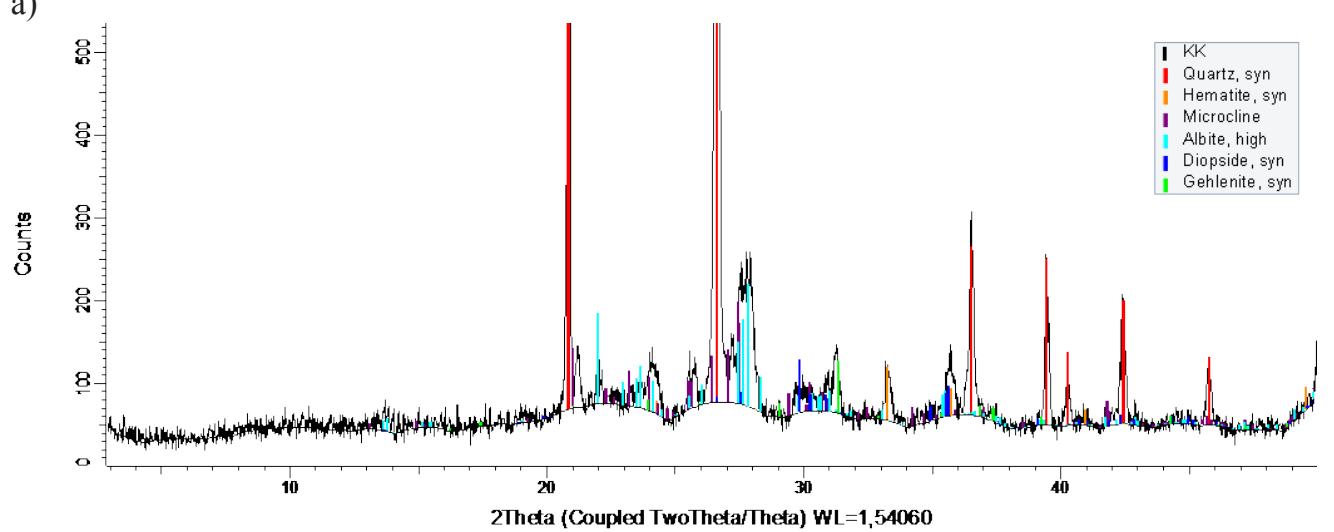

b)

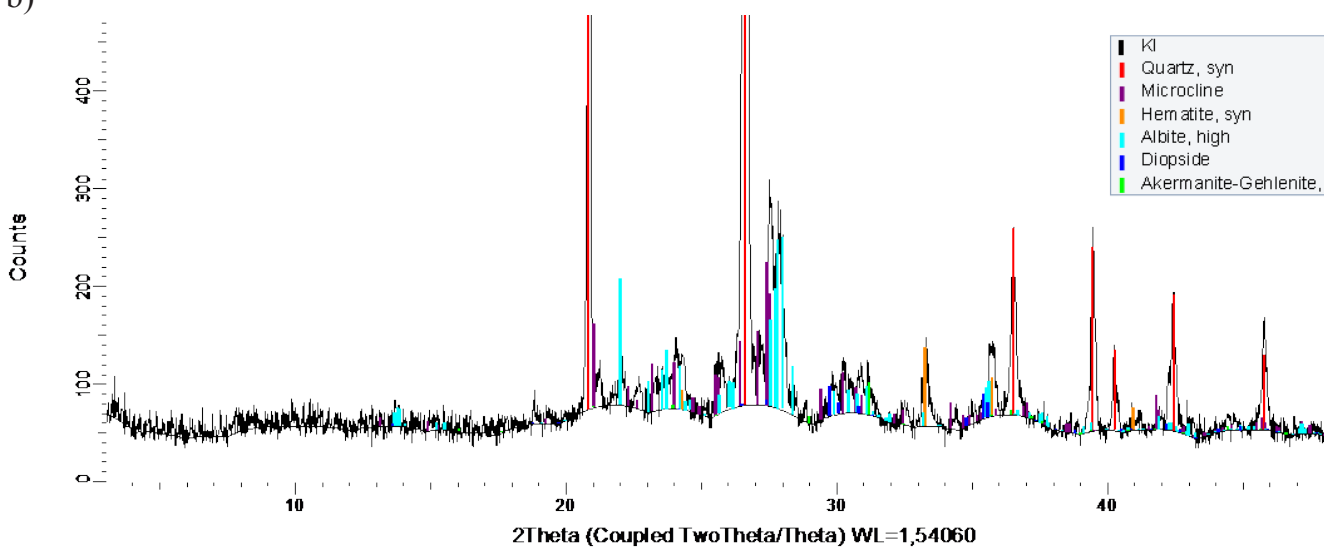

Fig. 1. Results of X-ray phase analysis of ceramics: a) control sample; b) modified Laksil 30.

The results of X-ray phase analysis (phase composition) of the control and modified Laksil 30 ceramic shard fired at a temperature of $1000{ }^{\circ} \mathrm{C}$ are shown in Table 2. A more amorphous phase is formed in a loam shard modified with Laksil 30 silica sol. 
Table 2. Results of X-ray phase analysis of the shard $\left(1000{ }^{\circ} \mathrm{C}\right)$.

\begin{tabular}{|l|c|c|}
\hline \multicolumn{1}{|c|}{ Phase composition } & Control (\%) & $\begin{array}{c}\text { Modified 0,1 \% Laksil 30, } \\
(\%)\end{array}$ \\
\hline gehlenite & $1,(5)$ & 1.6 \\
\hline diopside & 1.5 wollastonite $(3 \%)$ & 3.4 \\
\hline hematite & $2(4 \%)$ & 1.6 \\
\hline microcline & 16.5 & 14 \\
\hline albite & 18.5 & 15 \\
\hline quartz & 61 & 64 \\
\hline
\end{tabular}

Samples of ceramics after destruction were examined on a Micro and nanofocus X-ray research system for computed tomography General Electric V| tome |X S 240. The results of computed tomography are presented in Table. 3.

Table 3. Results of studies on a computed tomography.

\begin{tabular}{|l|c|c|c|c|}
\hline \multicolumn{2}{|c|}{$\begin{array}{c}\text { Klyuchishenskoye deposit } \\
\left(1000^{\circ} \mathrm{C}\right)\end{array}$} & Control & $\begin{array}{c}\text { Modified } \\
\text { Laksil 30 }\end{array}$ & $\begin{array}{c}\text { Unit } \\
\text { rev. }\end{array}$ \\
\hline \multirow{3}{*}{ pore volume } & $\min$ & $1.98 \mathrm{E}-06$ & $1.98 \mathrm{E}-06$ & $\mathrm{~mm}^{3}$ \\
\cline { 2 - 5 } & $\max$ & 0.3083203 & 1.799581 & $\mathrm{~mm}^{3}$ \\
\cline { 2 - 5 } & middle & $3.92 \mathrm{E}-05$ & 0.000143847 & $\mathrm{~mm}^{3}$ \\
\cline { 2 - 5 } & total & 4.0336836 & 5.3332722 & $\mathrm{~mm}^{3}$ \\
\hline total sample volume & & 123.9 & 123.9 & $\mathrm{~mm}^{3}$ \\
\hline $\begin{array}{l}\text { \% pore volume ratio } \\
\text { space to the total } \\
\text { sample volume }\end{array}$ & & 3.3 & 4.3 & $\%$ \\
\hline $\begin{array}{l}\text { the number of pores } \\
\text { in the investigated } \\
\text { volume of the sample }\end{array}$ & & 102911 & 37076 & \\
\hline
\end{tabular}

The results of studies on a General Electric V | tome | X S 240 micro and nanofocus research X-ray system for computed tomography confirm an increase in the content of the amorphous phase (glass phase) when the Klyuchischenskyoe loam is modified with silica Laksil 30, which, apparently, leads to an increase in the strength characteristics of the ceramics. Thus, in the structure of the modified sample, a decrease in the total number of pores is observed against the background of an increase in their average and maximum size with an increase in the percentage of pore volume in relation to the control sample by $30 \%$. A more optimal pore structure is formed, and small pores that reduce the strength characteristics of a ceramic shard are filled with a glass phase.

\section{Conclusion}

It is shown that the use of nanosized additives in ceramic production technology can increase the strength properties of a shard by using low-grade brick loams. Thus, the best results with the modification were shown by Laksil 30 silica sol in a quantitative ratio of $0.1 \%$ by weight of dry loam. An increase in the strength characteristics was observed due to an increase in the amorphous phase against the background of a general decrease in the porosity of the shard. 


\section{References}

1. D. Evin, A. Ucar, j.applthermaleng., 154, 573-584 (2019) DOI: 10.1016/j.applthermaleng.2019.03.102

2. A.W. Bashir, , B. C. Leite, C. EBE (2021) DOI: 10.1016/j.enbenv.2021.02.003

3. J. A.Rosas-Flores, D. Rosas-Flores, j.enbuild, 209 (2020) DOI: 10.1016/j.enbuild.2019.109698

4. A. Bogdanov, L. Abdrakhmanova, V. Khozin, CM 9, 14-17 (2017)

5. S. Schiavoni, F. D'Alessandro, F. Bianchi, F. Asdrubali, Renewable and Sustainable Energy Reviews 62, 988-1011 (2016) DOI: 10.1016/j.rser.2016.05.045

6. A. Khuzin, R. Mukhametrakhimov, A. Lamberov, and S. Egorova, in MATEC Web Conf. (2017) DOI:10.1051/matecconf/201710603011

7. D. S. Smirnov, T. R. Garaev, and D. R. Garipova, Izv. KGASU, 1 (2020)

8. B. P. Jelle, R. Baetens, A. Gustavsen, The Sol-Gel Handbook, 3-3, 1385-1412 (2015) DOI: $10.1002 / 9783527670819 . c h 45$

9. S. Rashidi, J. A. Esfahani, N. Karimi, j.rser, 91, 229-247 (2018) DOI: 10.1016/j.rser.2018.03.092

10. M. Kubiś, K. Pietrak, Ł. Cieślikiewicz, P. Furmański, M. Wasik, M. Seredyński, T. S. Wiśniewski, Łapka, P. JOBE 31, (2020) DOI: 10.1016/j.jobe.2020.101418

11. P. Rivero-Antúnez, R. Cano-Crespo, L. Esquivias, N. Rosa-Fox, C. de la, ZamoraLedezma, A. Domínguez-Rodríguez, V. Morales-Flórez, j.ceramint, 46, 12, 19723 19730 (2020) DOI: 10.1016/j.ceramint.2020.04.285

12.H. Parham, A. Kennedy, Y. Zhu, CSTE, 71, 15, 1739-1745 (2011) DOI: $10.1016 /$ j.compscitech.2011.08.005

13. V. Verma, S. C. Galaveen, L. Gurnani, T. Venkateswaran, A. Mukhopadhyay, j.ceramint, 46, 13, 21784-21789 (2020) DOI: 10.1016/j.ceramint.2020.05.159

14. I. Ahmad, , M. Islam, j.jallcom, 788, 219-230 (2019) DOI: $10.1016 /$ j.jallcom.2019.02.226

15. M. A. Akl, A. M. Youssef, M.M. Al-Awadhi J. Anal. Bioanal.Tech., 4, (2013) DOI: 10.4172/2155-9872.1000174

16. O. Tapasztó, L. Tapasztó, M. Markó, F. Kern, R. Gadow, C. Balázsi, j.cplett, 511, 4-6, 340-343, (2011) O. Tapasztó, L. Tapasztó, M. Markó, F. Kern, R. Gadow, C. Balázsi, j.cplett, 511, 4-6, 340-343, (2011) DOI: 10.1016/j.cplett.2011.06.047

17. A. Bogdanov, L. Abdrakhmanova, AZ Druck und Datentechnik GmbH, 264-266 (2016)

18. G. Lagaly, M. Ogawa, I. Dékány Developments in Clay Science, 1, 309-377 (2006) DOI: 10.1016/S1572-4352(05)01010-X

19. A. Bogdanov, L. Abdrakhmanova, IOP Conf. Ser.: Mater. Sci. Eng., 890, 1, (2020) DOI:10.1088/1757-899X/890/1/012090

20. S. Işçi, F. S. Güner, Ö. I. Ece, N. Güngör, j.porgcoat, 54, 1, 28-33, (2005) DOI:10.1016/j.porgcoat.2005.03.002

21. A. Aimable, , T. Chartier, In Reference Module in Materials Science and Materials Engineering, (2020) DOI: 10.1016/b978-0-12-803581-8.11768-0

22. G. V. Franks, F. F. Lange, J EUR. CERAM. SOC., 21, 7, 893-899 (2001) DOI: $10.1016 / \mathrm{S} 0955-2219(00) 00278-8$

23. P. E. Bulanov, E. A. Vdovin, L. F. Mavliev, and D. A. Kuznetsov, in IOP Conf. Ser. Mater. Sci. Eng. (2018) DOI: 10.1088/1757-899X/327/3/032014 